\title{
Mecanismos Moleculares de Adesão e Colonização da Mucosa Gástrica pela Helicobacter pylori e suas Implicações Clínicas
}

\section{Molecular Mechanisms for Adhesion and Colonization of Human Gastric Mucosa by Helicobacter pylori and its Clinical Implications}

\author{
Elisabete COELHO ${ }^{1}$, Ana MAGALHÃES $\varangle^{2,3}$, Mário DINIS-RIBEIRO ${ }^{1,4,5}$, Celso A. REIS $1,2,3$ \\ Acta Med Port 2016 Jul-Aug;29(7-8):476-483 - http://dx.doi.org/10.20344/amp.6651
}

RESUMO

Introdução: A infeção por Helicobacter pylori é muito prevalente mundialmente, e está associada à progressão da cascata de carcinogénese gástrica, sendo um dos principais fatores de risco para o desenvolvimento de carcinoma gástrico. São vários os fatores determinantes para a infeção e desenvolvimento de patologia gástrica, incluindo fatores ambientais, fatores genéticos do hospedeiro, e fatores de virulência da bactéria.

Material e Métodos: Neste trabalho, é apresentada uma revisão do estado da arte sobre os fatores determinantes da infeção e sobre os mecanismos moleculares de adesão da Helicobacter pylori à mucosa gástrica recentemente descritos e a sua possível aplicação terapêutica.

Resultados: A adesão da Helicobacter pylori ao epitélio gástrico é uma etapa fundamental da patogénese gástrica, permitindo o acesso da bactéria a nutrientes, e a ação de diversos fatores de virulência da bactéria, promovendo, desta forma, a recorrência da infeção e a progressão na cascata de carcinogénese gástrica.

Discussão: A erradicação da infeção por Helicobacter pylori é a melhor estratégia preventiva disponível contra o carcinoma gástrico, principalmente quando feita antes do aparecimento de lesões pré-neoplásicas. O aumento da resistência aos antibacterianos e as taxas de erradicação, por vezes aquém do esperado, contribuem para a procura de alternativas de tratamento.

Conclusão: O desenvolvimento de novas estratégias terapêuticas focadas nos mecanismos moleculares de adesão da Helicobacter pylori é muito promissor, no entanto são necessários estudos futuros sobre a sua eficácia in vivo e toxicidade.

Palavras-chave: Adesinas Bacterianas; Carcinogénese; Factores de Virulência; Helicobacter pylori; Infecções por Helicobacter; Neoplasias Gástricas.

\section{ABSTRACT}

Introduction: Helicobacter pylori infection is very prevalent worldwide and is associated with the progression of the gastric carcinogenesis cascade, being one of the main risk factors for the development of gastric carcinoma. Several factors are determinant for the infection and for the development of gastric disease, including environmental factors, host genetic factors and virulence factors of the bacteria.

Material and Methods: In this review, we present an overview of the current knowledge on the determinants of the infection and on the recently described molecular mechanisms of Helicobacter pylori adhesion to the gastric mucosa, as well as its possible future therapeutic application.

Results: The adhesion of Helicobacter pylori to the gastric epithelium is critical for gastric pathogenesis, allowing bacterial access to nutrients and the action of bacterial virulence factors, promoting recurrence of the infection and the progression of the gastric carcinogenesis pathway.

Discussion: Eradication of Helicobacter pylori infection is the best preventive strategy available against gastric cancer, mainly if it is achieved before the development of pre-neoplastic lesions. The increase in antibiotics resistance, together with the eradication failures in some patients, has promoted the development of alternative treatments.

Conclusion: The new therapeutic strategies, focused on the molecular mechanism of Helicobacter pylori adhesion, are very promising; however, future studies are needed to evaluate its in vivo efficiency and toxicity.

Keywords: Adhesins, Bacterial; Carcinogenesis; Helicobacter Infections; Helicobacter pylori; Stomach Neoplasms; Virulence Factors.

\section{INTRODUÇÃO}

Metade da população mundial está infetada pela Helicobacter pylori (H. pylori), sendo a infeção adquirida principalmente na infância. ${ }^{1} \mathrm{~A}$ transmissão da infeção ocorre por contacto direto pessoa-pessoa sendo aceites as vias oral-oral e fecal-oral, embora os mecanismos exatos de trans- missão sejam desconhecidos e provavelmente múltiplos. ${ }^{2}$

Em Portugal, há uma prevalência da infeção por $H$. pylori aos 13 anos de idade de $66,2 \%$, com uma taxa de incidência de 4,1/100 pessoas-ano entre os $13-17$ anos, ${ }^{1}$ sendo que a prevalência em adultos ultrapassa os $80 \%{ }^{3}$

1. Faculdade de Medicina. Universidade do Porto. Porto. Portugal.

2. i3S - Instituto de Investigação e Inovação em Saúde. Universidade do Porto. Porto. Portugal.

3. Instituto de Patologia e Imunologia Molecular. Universidade do Porto. Porto. Portugal.

4. Serviço de Gastroenterologia. Instituto Português de Oncologia. Porto. Portugal.

5. CIDES/CINTESIS. Universidade do Porto. Porto. Portugal.

$\triangle$ Autor correspondente: Ana Magalhães. amagalhaes@ipatimup.pt

Recebido: 28 de maio de 2015 - Aceite: 06 de março de 2016 | Copyright @ Ordem dos Médicos 2016 
Num outro estudo, verificou-se que $36,0 \%$ dos indivíduos infetados por $H$. pylori apresentam gastrite crónica atrófica (GCA), enquanto a infeção por $H$. pylori foi diagnosticada em $97,7 \%$ dos casos de GCA. A maioria dos cancros gástricos de ambos os tipos histopatológicos $(96,7 \%$ no tipo intestinal e 93,3\% no tipo difuso) desenvolvem-se em doentes com positividade para anticorpos anti-H. pylori. ${ }^{4}$

O cancro gástrico é a quarta e quinta causa mais comum de cancro em homens e mulheres, respetivamente, sendo responsável por 952000 novos casos e 723000 mortes por ano em todo o mundo. ${ }^{5}$ Em Portugal, o cancro gástrico é a quinta e quarta causa mais comum de cancro em homens e mulheres, respetivamente, sendo responsável por 3018 novos casos e 2285 mortes por ano. ${ }^{5}$

Neste trabalho é feita uma revisão do estado da arte sobre os fatores determinantes da infeção e sobre os mecanismos moleculares de adesão da $H$. pylori à mucosa gástrica recentemente identificados. Adicionalmente, sendo a infeção por $H$. pylori um dos principais fatores de risco implicados, pretendemos alertar os profissionais de saúde para o problema de saúde pública que é o carcinoma gástrico e evidenciar a futura possibilidade da existência de terapêuticas moleculares direcionadas para a erradicação da infeção.

\section{MATERIAL E MÉTODOS}

Realizámos uma revisão não sistemática da literatura integralmente disponível na PubMed (utilizando termos como 'Helicobacter pylori', 'Adesinas', 'Fatores de virulência', 'Carcinoma gástrico'). Apenas foram incluídos artigos disponíveis em Inglês ou Português. Demos preferência a literatura relacionada com a realidade da infeção por $H$. pylori em Portugal. Posteriormente, a informação foi organizada e compilada de modo a ser possível uma abordagem atual e concisa do tema proposto.

\section{RESULTADOS}

\section{Fatores determinantes da infeção e desenvolvimento de patologia gástrica \\ Fatores ambientais}

A infeção por $H$. pylori está relacionada com as condições de vida na infância. Uma baixa condição socioeconómica durante a infância, avaliada pelo número de pessoas que habitam numa mesma casa, é apontada como o principal fator de suscetibilidade à infeção., ${ }^{1,2} \mathrm{O}$ facto de se continuar a viver em casas sobrelotadas, com muitas crianças, também aumenta a prevalência da infeção. ${ }^{2}$

Fatores comportamentais como o tabaco e o consumo de sal estão também associados à infeção por $H$. pylori. ${ }^{1,6}$ Bastos $\mathrm{J}$ et al encontraram uma associação positiva entre ser fumador aos 13 anos de idade e a incidência da infeção, independentemente da classe social do indivíduo. ${ }^{1}$ Foi demonstrado que o consumo excessivo de sal provoca uma hiperplasia do epitélio gástrico, facilitando a colonização pela H. pylori. Adicionalmente, a lesão epitelial aumenta o potencial mutagénico resultando num aumento do risco de carcinoma gástrico. ${ }^{6}$

A deficiência em ferro aumenta a severidade e acelera o desenvolvimento de lesões gástricas, quer por indução de stress oxidativo nas células epiteliais gástricas (por interferência com o metabolismo oxidativo mitocondrial), quer por efeito direto sobre a $H$. pylori (ver fatores de virulência da bactéria) ${ }^{7}$

\section{Fatores genéticos do hospedeiro}

As primeiras barreiras de defesa contra a $H$. pylori são o muco produzido pelas células epiteliais gástricas e as células do sistema imunitário residentes na lâmina própria ou recrutadas durante a infeção. A deteção de pathogen-associated molecular patterns (PAMPs) pelas células epiteliais e da imunidade inata ocorre via quatro classes distintas de recetores da imunidade inata, os pattern recognition receptores (PRRs). A bactéria evoluiu de modo a evitar a indução de respostas pró-inflamatórias potentes, assim como a consequente eliminação e imunidade adaptativa, por dois principais mecanismos: evasão da deteção por tool like receptors (TLRs) pró-inflamatórios e ativação preferencial e manipulação de TLRs e C-type lectin receptors (CLRs) anti-inflamatórios. ${ }^{8} \mathrm{~A}$ deteção da $H$. pylori pelos NOD-like receptors (NLRs) e subsequente ativação do inflamassoma e suas vias de sinalização é crucial para um controlo eficiente da infeção, através da ação do NOD1 e da interleucina $1 \beta$ (IL-1ß), e simultaneamente reduz a resposta excessiva das células T e o dano tecidular, pela ação da interleucina 18 (IL-18) ${ }^{9,10}$

Polimorfismos que aumentem a expressão de genes pró-inflamatórios, que diminuam fatores anti-inflamatórios ou nos TLRs aumentam o risco de doença associada à infeção por $H$. pylori. ${ }^{11}$ A IL-1 $\beta$ (codificada pelo gene IL-1B) é uma potente citoquina pró-inflamatória e inibidora da secreção ácida gástrica que tem um importante papel em iniciar e amplificar a resposta inflamatória à $H$. pylori. A ação da IL-1 $\beta$ é contrabalançada pela interleucina 1ra (IL-1ra) (codificada pelo gene IL-1RN) a qual se liga competitivamente aos recetores da IL-1 $\beta$. O fator de necrose tumoral $\alpha$ (TNF- $\alpha$ ) tem uma ação semelhante à IL-1 $\beta$ e os seus níveis estão aumentados na infeção por $H$. pylori. ${ }^{12}$ Polimorfismos destas citoquinas vão favorecer uma resposta pró-inflamatória severa e persistente com desenvolvimento de gastrite atrófica. ${ }^{12,13}$ A GCA inicia-se no antro gástrico e estende-se proximalmente para o cárdia. A função secretora gástrica diminui à medida que a mucosa funcional atrofia culminando numa diminuição da produção de pepsinogénio e hipocloridria. ${ }^{4,12}$

A resposta imune celular é importante tanto na patogénese como na resolução da infeção. ${ }^{11} \mathrm{~A}$ resposta predominante é mediada por células $\mathrm{T}$ efetoras $\mathrm{CD} 4^{+}$, particularmente Th1 e Th17 e as suas citoquinas, sendo essencial no controlo da infeção. ${ }^{8}$ A produção de citoquinas pró-inflamatórias associadas à resposta Th1 e Th17 e ativação macrofágica com secreção de interferon y (IFN-ү) vão culminar na indução de atrofia gástrica. ${ }^{11}$ 


\section{Fatores de virulência da bactéria}

A H. pylori é uma bactéria Gram negativa, microaerofílica, em forma de espiral que se adaptou ao nicho ecológico determinado pelo muco gástrico, onde há pouca competição por parte de outros micro-organismos. ${ }^{14}$ Para sobreviver neste ambiente hostil, a bactéria sintetiza grandes quantidades de urease, enzima que hidrolisa a ureia endógena em amónia e dióxido de carbono, neutralizando o $\mathrm{pH}$ ácido do suco gástrico. ${ }^{2}$ Além disso, a $H$. pylori possui entre dois e seis flagelos unipolares com 3 - $5 \mu \mathrm{m}$ que the permitem mover-se através do muco gástrico. ${ }^{15}$

As diferentes estirpes de $H$. pylori são geneticamente muito polimórficas, sendo este polimorfismo determinante para a sua patogenicidade. O gene cytotoxic-associated gene $A(\operatorname{cag} A)$ é um marcador da presença da ilha de patogenicidade cag (cagPAl) no genoma das diferentes estirpes. ${ }^{16}$ Esta ilha de patogenicidade pode estar presente, ausente ou incompleta (não funcional), sendo encontrada em $60 \%$ - 70\% das estirpes de H. pylori. ${ }^{11,14} \mathrm{~A}$ cagPAI contém aproximadamente 30 genes, incluindo o gene cag $A$ e os genes que codificam o sistema de secreção tipo IV (T4SS). ${ }^{11} \mathrm{O}$ produto de secreção do gene cagA é a oncoproteína cytotoxin-associated antigen $A$ (CagA) a qual é transportada para o interior das células epiteliais gástricas através do T4SS. ${ }^{16}$ O T4SS é um complexo multiproteíco que inclui as proteínas CagY, uma proteína estrutural que confere estabilidade ao canal e permite a evasão imune, e CagL (presente na extremidade do canal). ${ }^{11}$ É a interação entre a CagL e a integrina $\alpha_{5} \beta_{1}$ das células epiteliais gástricas que permite a injeção da CagA e ativação de vias de sinalização nas células gástricas. ${ }^{11,17,18}$ Uma vez internalizada nas células do hospedeiro, a proteína CagA é fosforilada no sítio C-terminal EPIYA (Glu-Pro-lle-Tyr-Ala) por cinases da família SRC. ${ }^{19}$ Depois de fosforilada, a CagA interage com vias de sinalização intracelulares, culminando na ativação de moléculas como NF-kB, SHP2 e ERK. ${ }^{11,16,20} \mathrm{O}$ resultado da ação da CagA é uma desorganização morfológica das células epiteliais, com efeitos na polaridade e adesão intercelular, e produção de citoquinas pró-inflamatórias, como a interleucina 8 (IL-8), interleucina 1 (IL-1) e TNF-a. A CagA está fortemente implicada na carcinogénese gástrica, principalmente no carcinoma tipo intestinal. ${ }^{11,14,16,20}$ A CagA é polimórfica pelo que pode ter diferentes efeitos na sinalização celular e, consequentemente conferir diferente risco de doença. ${ }^{11}$ As diferenças nos resíduos de tirosina que são fosforilados sugerem que diferentes proteínas CagA podem ter atividade biológica distinta, o que pode explicar diferenças na incidência de cancro gástrico a nível mundial. ${ }^{20,21} \mathrm{~A}$ CagA pode também interferir com as vias de sinalização e com as funções celulares do hospedeiro no seu estado não fosforilado. ${ }^{22}$

Apesar da depleção de ferro ter efeitos nas células epiteliais gástricas, as suas principais consequências estão relacionadas com efeitos diretos sobre a $H$. pylori, alterando significativamente o perfil proteómico da bactéria, nomeadamente por modulação da expressão de CagA. A depleção de ferro é capaz de induzir o acoplamento do T4SS e de aumentar a expressão e translocação da oncoproteína para as células do hospedeiro. Este achado está de acordo com o facto de doentes com lesões gástricas pré-malignas mais severas terem tipicamente hipocloridria, o que diminui a absorção de ferro. Assim, a depleção de ferro associada a infeção por estirpes $H$. pylori cag $A^{+}$deve ser considerada fator de risco para desenvolvimento de cancro gástrico. ${ }^{7}$

O gene vacuolating cytotoxin gene (vacA) codifica a exotoxina vacuolating cytotoxin (VacA) cuja expressão está associada à expressão da CagA.${ }^{14} \mathrm{~A}$ VacA é composta por duas subunidades - p33 e p55 - e está especialmente adaptada ao estômago. É ativada pelo ácido gástrico sendo que na forma ativa é resistente ao ácido gástrico e à pepsina. ${ }^{11} \mathrm{O}$ gene vacA pode variar em três regiões: peptídeo sinal (s1 ou s2), região intermédia - p33 (i1 ou i2) e região média - p55 (m1 ou m2). ${ }^{11} A$ forma $\mathrm{s} 1 / \mathrm{i} 1 / \mathrm{m} 1$ é completamente ativa enquanto a forma s2/i2/m2 é inativa. ${ }^{11}$ Virtualmente, todas as estirpes $H$. pylori têm o gene vacA e $40 \%$ - $50 \%$ das estirpes produzem proteína, sendo as formas intermédias as mais comuns na população. ${ }^{11} \mathrm{~A}$ principal ação da exotoxina é a vacuolização celular por formação de poros na membrana das células epiteliais. ${ }^{11,14} \mathrm{~A}$ VacA está ainda implicada na despolarização membranar, apoptose e adesão intercelular. ${ }^{14} \mathrm{~A}$ exotoxina interfere com vias de sinalização iniciadas pelo TCR ( $T$ cell receptor), nomeadamente ligando-se à $\beta_{2}$-integrina e bloqueando o influxo de cálcio, parando o ciclo celular em G1/S, culminando na inibição da proliferação e ativação de células T.11,14,20 Assim, a VacA está implicada na persistência da infeção. ${ }^{20}$ In vitro mostrou-se a ação inibitória da VacA sobre as células parietais, corroborando a sua implicação na ulceração, hipocloridria e atrofia gástrica pré-maligna, independente dos genes cag. ${ }^{11}$

A proteína VacA afeta a atividade das células $T$ de modo indireto, promovendo a diferenciação preferencial de células $\mathrm{T}$ naive em células $\mathrm{T}$ reguladoras (Tregs). A diferenciação de células Tregs requer a interação direta entre células T naive e células dendríticas tolerogénicas, ou seja, células dendríticas que já foram expostas à $H$. pylori na mucosa gástrica ou nos gânglios linfáticos. ${ }^{8} \mathrm{~A}$ ação das células Tregs é levada a cabo por citoquinas imunossupressoras, como a interleucina 10 (IL-10) e o fator de crescimento tumoral $\beta$ (TGF- $\beta$ ), que suprimem a produção de IL-8 e a ação das células de memória. ${ }^{11}$ Assim, as células Tregs são importantes tanto na promoção da persistência da infeção como no controlo da inflamação. ${ }^{11}$

O gene duodenal ulcer-promoting gene $A(d u p A)$ é um marcador de desenvolvimento de úlcera duodenal e também um fator protetor para a atrofia gástrica, metaplasia intestinal e carcinoma gástrico. O dupA está relacionado com um aumento da produção de IL-8 e com uma maior infiltração neutrófila, nomeadamente na mucosa do antro gástrico. Estes resultados estão de acordo com os resultados in vivo que mostram níveis elevados de IL-8 e grande infiltração neutrófila no antro gástrico dos doentes com úlcera duodenal e também com a observação clínica de que a úlcera duodenal é protetora de cancro gástrico. ${ }^{23}$ 
Mecanismos moleculares da adesão e colonização da Helicobacter pylori

A colonização do estômago pela H. pylori é dependente da atividade da urease e da forma helicoidal da bactéria. $\mathrm{O}$ $\mathrm{pH}$ gástrico acídico limita a colonização uma vez que a bactéria só sobrevive alguns minutos no lúmen gástrico. Assim, a $H$. pylori tem que migrar rapidamente até ao epitélio superficial onde as mucinas formam uma camada de muco que envolve a bactéria. Pela ação da urease, o pH local aumenta e, graças à sua forma helicoidal, a bactéria consegue mover-se até estabelecer contacto com o epitélio gás- trico. ${ }^{8}$ A adesão da $H$. pylori às células epiteliais gástricas é essencial para a colonização da mucosa gástrica e para a manutenção de uma infeção crónica. ${ }^{24}$

\section{Importância dos glicanos expressos na mucosa gástrica}

A adesão da $H$. pylori é mediada por adesinas que se ligam a glicanos expressos na mucosa gástrica - os antigénios Lewis. Os antigénios Lewis são sintetizados pela ação sequencial de glicosiltranferases, sendo a sua expressão dependente da atividade das enzimas Secretor (Se ou FUT2) e Lewis (Le ou FUT3) (Fig. 1). ${ }^{25,26}$
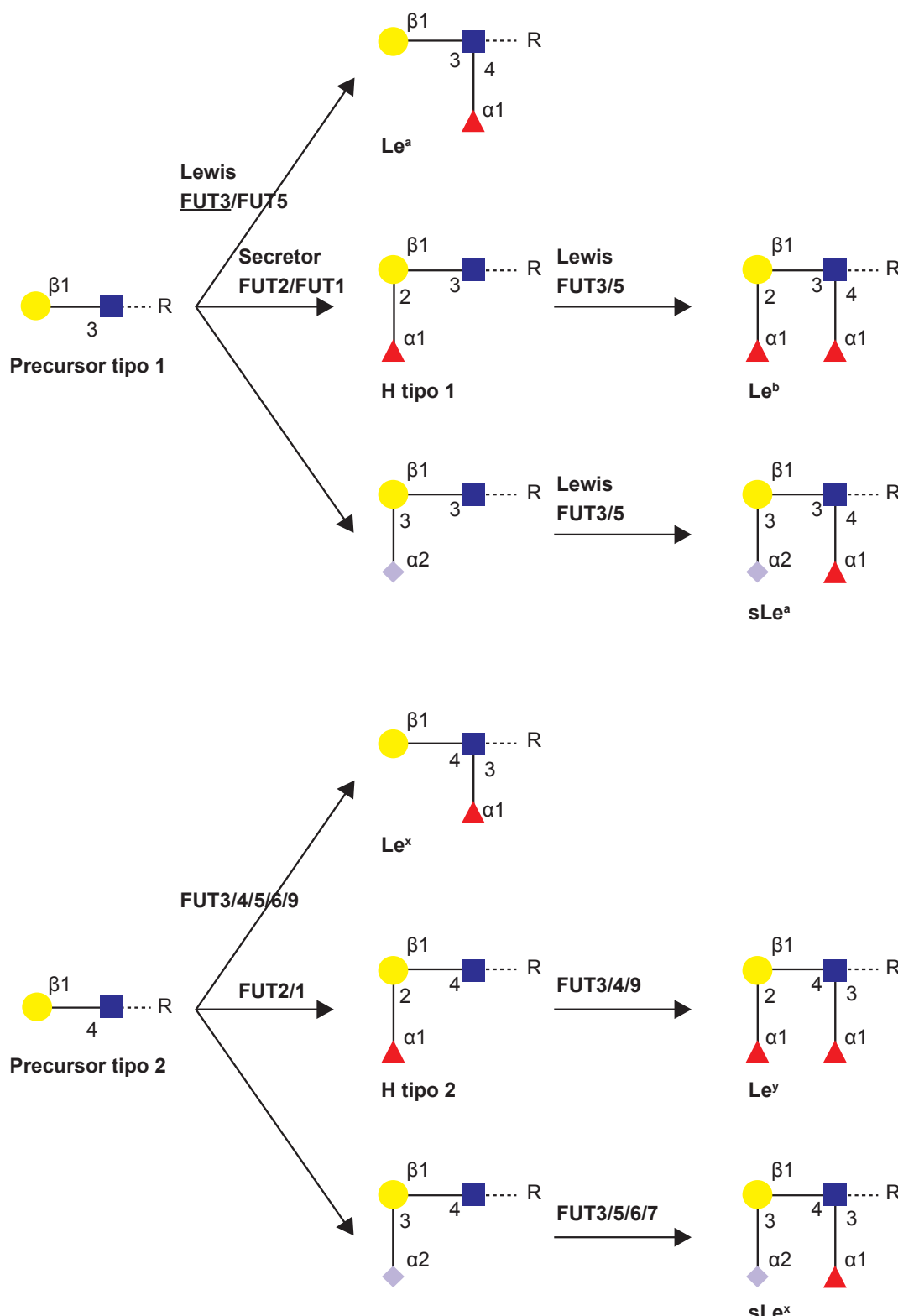
Estes antigénios podem ser tipo 1 ou tipo 2 dependendo se a ligação entre a galactose e a $\mathrm{N}$-acetilglucosamina é $\beta 1,3$ ou $\beta 1,4$, respetivamente. O destino do precursor tipo 1 depende do estado secretor, ou seja, se o indivíduo tem ou não a enzima Se ativa. Indivíduos com enzima Se ativa - indivíduos secretores (80\% da população caucasiana) produzem maioritariamente estruturas $\mathrm{H}$ tipo 1 que depois são modificadas pela enzima Le formando Lewis b $\left(L^{b}{ }^{b}\right)$. Caso o indivíduo seja não secretor $(20 \%)$, ou seja, se a enzima Se não for ativa, o precursor tipo 1 sofre maioritariamente a ação da enzima Le. Assim, os indivíduos não secretores produzem uma maior quantidade de Lewis a $\left(\operatorname{Le}^{\mathrm{a}}\right)$ e não produzem $\mathrm{H}$ tipo 1 ou Le $\mathrm{L}^{\mathrm{b}} .^{25,27} \mathrm{~A}$ cadeia precursora tipo 1 pode ainda ser sialilada antes de ser fucosilada pela enzima Le, sintetizando-se estruturas sialiladas, nomeadamente sialil-Lewis a (sLe ${ }^{a}$ ) (Fig. 1). ${ }^{28}$ Os polimorfismos do gene Secretor encontrados na população portuguesa ocorrem no domínio catalítico e resultam em enzimas inativas. O polimorfismo nonsense FUT2 G428A é o mais frequentemente encontrado (89\%), mas foram também descritos polimorfismos missense, FUT2 G739A e FUT2 T839C. ${ }^{25,29}$ Estudos recentes demonstram que o polimorfismo FUT2 G739A resulta numa forma ativa in vivo. ${ }^{30}$

Na mucosa gástrica a expressão de antigénios Lewis está associada ao padrão de expressão de mucinas gástricas. No epitélio superficial são expressos maioritariamente antigénios Lewis do tipo $1\left(\mathrm{Le}^{\mathrm{a}}, \mathrm{Le}^{\mathrm{b}}\right)$ e a mucina MUC5AC, enquanto nas glândulas profundas há expressão de antigénios Lewis do tipo 2 (Lewis $x, L^{x}$ e Lewis $y, L^{y}$ ) e da mucina MUC6. ${ }^{31,32}$

A colonização pela $H$. pylori acontece normalmente no epitélio superficial onde a principal constituinte do muco é a MUC5AC. ${ }^{14,33} \mathrm{~A} H$. pylori raramente coloniza as glândulas profundas onde predomina a mucina MUC6, com glicanos do tipo a1,4-GIcNAc terminais. ${ }^{14,33}$ Estes glicanos têm uma função antibiótica natural, inibindo a motilidade e o crescimento da bactéria e induzindo alterações na sua morfologia, ${ }^{33}$ culminando num aumento da ação macrofágica e da resposta dos linfócitos T sobre a bactéria. ${ }^{14}$

Para além de serem expressos na mucosa gástrica do hospedeiro, a bactéria também expressa alguns destes glicanos no antigénio $O$ do lipopolissacarídeo (LPS) da parede celular, predominantemente Le ${ }^{\mathrm{x}}$ e Le ${ }^{y}{ }^{34}$ Assim, o LPS é considerado importante na evasão da bactéria à imunidade inata do hospedeiro, facilitando a colonização inicial. O LPS pode ainda sofrer variações do antigénio $O$ que podem resultar em tolerância imunológica à bactéria ou na indução da formação de autoanticorpos contra o epitélio gástrico. ${ }^{14}$

\section{Adesinas e mecanismos de adesão}

A principal adesina responsável pela interação entre a H. pylori e a mucosa gástrica é a Blood group antigen-binding adhesin (BabA), cujos ligandos são as estruturas fucosiladas do tipo 1, nomeadamente o Le ${ }^{\mathrm{b}}$ e o H tipo 1 (Fig. 1). ${ }^{25,27,35} \mathrm{O}$ gene que codifica a BabA possui duas isoformas: babA1 e babA2, sendo a isoforma babA2 aquela que produz uma adesina funcional. ${ }^{14} \mathrm{O}$ gene babA2 está signi- ficativamente associado à inflamação gástrica ativa e crónica, bem como ao desenvolvimento de adenocarcinoma gástrico. ${ }^{27}$ Algumas das estirpes $H$. pylori não expressam a adesina BabA mas têm o gene babA que pode ser ativado por recombinação génica. ${ }^{20,25} A$ infeção da mucosa gástrica pela $H$. pylori é dependente do estado secretor. Os indivíduos secretores são capazes de sintetizar antigénios $\mathrm{H}$ tipo 1 e estas estruturas estão associadas a uma maior ligação entre as estirpes BabA positivas e a mucosa gástrica. ${ }^{25}$

A sialic acid-binding adhesin (SabA) foi identificada como sendo uma hemaglutinina pela sua capacidade de aglutinar os eritrócitos de modo dependente do ácido siálico. ${ }^{36}$ A SabA é uma adesina polimórfica na sua capacidade de ligação a glicanos sialilados, sendo os seus principais

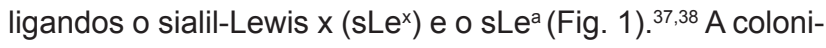
zação da mucosa gástrica pela $H$. pylori resulta em inflamação da mucosa e alteração da expressão de glicanos, com aumento dos glicanos sialilados e diminuição concomitante dos glicanos fucosilados. ${ }^{37,39} \mathrm{~A} \mathrm{H}$. pylori, principalmente estirpes cagPAl positivas, é capaz de induzir enzimas responsáveis pela biossíntese de $s \mathrm{~L}^{\mathrm{x}}$, nomeadamente a B3GIcNAcT5. ${ }^{40,41}$ A sobreexpressão de sLe ${ }^{x}$ facilita a adesão mediada pela SabA. ${ }^{37,39} \mathrm{~A}$ adesão mediada pela SabA não é influenciada pelo estado secretor. ${ }^{37,39}$ Estirpes com mutação/deleção do gene babA continuam a aderir ao epitélio gástrico, preferencialmente à mucosa inflamada, ${ }^{38} \mathrm{su}$ gerindo que a interação SabA-sLe ${ }^{x}$ promove a colonização pela $H$. pylori em doentes com baixa expressão de $\operatorname{Le}^{b}{ }^{37,39}$ A SabA é importante na adesão e ativação de neutrófilos. ${ }^{38}$ A infeção por H. pylori está caracteristicamente associada a uma densa infiltração neutrófila do epitélio superficial. Estes neutrófilos podem expressar ligandos sialilados que são reconhecidos pela SabA e esta interação resulta em ativação dos neutrófilos cujos metabolitos oxidados promovem dano tecidular. ${ }^{38} \mathrm{~A}$ bactéria é capaz de modular a expressão do gene sabA sugerindo que a expressão de SabA pode ser alterada rapidamente em resposta à variação do perfil de glicanos ou à atividade inflamatória. ${ }^{38,39} \mathrm{~A}$ modulação da expressão do gene sabA e a ligação ao sLe ${ }^{\mathrm{x}}$ podem beneficiar a $H$. pylori permitindo-lhe escapar a locais onde a resposta imune de defesa do hospedeiro é mais vigorosa, sendo esta adaptação essencial para a cronicidade da infeção. ${ }^{38,39}$ O status SabA é instável no estômago e não está relacionado com a expressão de CagA.$^{38} \mathrm{~A}$ expressão de SabA está inversamente relacionada com a secreção ácida gástrica. ${ }^{42}$ Assim, a SabA está associada a carcinoma gástrico, metaplasia intestinal e gastrite atrófica; e está negativamente associada a úlcera duodenal. ${ }^{38}$

Recentemente foi identificado uma nova adesina, LacdiNAc - binding adhesin (LabA) ${ }^{43}$ que se liga especificamente aos resíduos LacdiNAc da mucina MUC5AC. Os resíduos LacdiNAc são expressos na mucosa gástrica humana em regiões com expressão de MUC5AC e onde ocorre colonização pela $H$. pylori. Esta interação mediada pela LabA que promove a ligação aos resíduos lacdiNAc da MUC5AC pode ser um fator adicional para o tropismo da $H$. pylori para a mucosa gástrica. 


\section{DISCUSSÃO}

A adesão é um passo muito importante para a patogénese associada à infeção por $H$. pylori (Fig. 2). A adesão garante à bactéria não só o acesso aos nutrientes provenientes do hospedeiro como também promove a ação de outros fatores de virulência - a adesão mediada pela BabA promove a translocação da CagA e consequente indução da inflamação gástrica. ${ }^{44}$ Os fatores de virulência (CagA, VacA, $\operatorname{dupA}$, etc.) podem ser injetados nas células hospedeiras ou libertados em vesículas. ${ }^{22}$ As suas ações patogénicas promovem a infeção e a resposta inflamatória e estão fortemente implicadas na cascata de carcinogénese gástrica (inflamação $\rightarrow$ GCA $\rightarrow$ metaplasia $\rightarrow$ displasia $\rightarrow$ carcinoma), sendo a sua progressão dependente de polimorfismos do hospedeiro e das características da bactéria. ${ }^{39} \mathrm{~A}$ infeção por estirpes $H$. pylori que contêm babA2, cagA e o alelo vacAs1 confere o maior risco de desenvolvimento de carcinoma gástrico. ${ }^{45}$

A erradicação da $H$. pylori é a melhor estratégia preventiva disponível contra o carcinoma gástrico, principalmente se feita antes do aparecimento de lesões pré-neoplásicas e está indicada em doentes de alto risco. ${ }^{46}$ Existe alguma controvérsia quanto à associação da erradicação com o aumento da secreção gástrica e consequente esofagite de refluxo. ${ }^{11}$ No entanto, os estudos mais recentes mostram que a erradicação da infeção não causa nem exacerba o refluxo gastroesofágico. ${ }^{47}$ Assim, a presença de refluxo gastroesofágico não deve impedir a erradicação da $H$. pylori nos doentes em que está indicada. ${ }^{46}$ Atualmente, estão a ser desenvolvidos estudos no sentido de avaliar a implementação de programas de erradicação da infeção por H. pylori. ${ }^{48}$

A terapêutica mais frequentemente utilizada atualmente consiste num inibidor da bomba de protões em combinação com antibióticos ${ }^{46,49}$ No entanto, a baixa adesão à terapêutica, o aumento da resistência aos antibacterianos e as taxas de erradicação muitas vezes aquém do esperado, contribuem para a procura de tratamentos alternativos. ${ }^{46,50}$ Embora a possibilidade da vacinação contra a $H$. pylori tenha sido estabelecida, a esterilização imune nunca foi atingida no modelo animal e nenhuma vacina foi para além dos ensaios clínicos de fase 1, pelo que continua em estudo o desenvolvimento de uma vacina segura e eficaz para uso humano. ${ }^{51-53}$

Têm sido realizadas várias tentativas de desenvolvimento de novas estratégias terapêuticas. A utilização de micro e nanopartículas muco-adesivas que contactam diretamente com a $H$. pylori através das suas propriedades de adesão e que podem apresentar diferentes técnicas de libertação do fármaco têm mostrado resultados muito promissores.$^{54}$ As microesferas de quitosano são um exemplo de compostos com capacidade antimicrobiana e de aderir

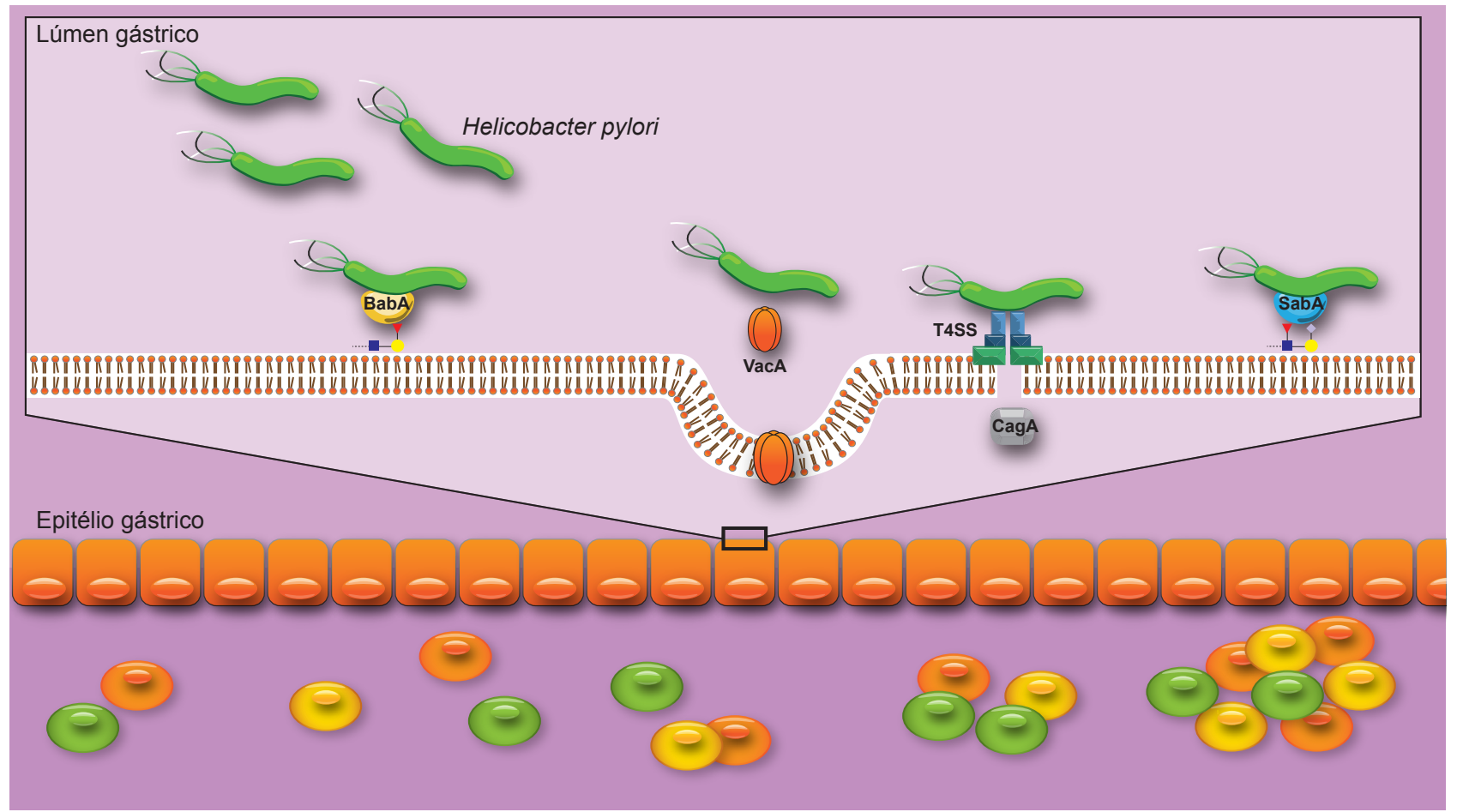

Figura 2 - Colonização da mucosa gástrica pela Helicobacter pylori: A adesina BabA é a principal responsável pela adesão da bactéria à mucosa gástrica mediando a interação com estruturas fucosiladas do tipo 1 (Le $\mathrm{b}^{\mathrm{b}}, \mathrm{H}$ tipo 1). A adesão garante à bactéria acesso a nutrientes e permite a injeção de fatores de virulência nas células do epitélio gástrico, nomeadamente a CagA e a VacA. A oncoproteína CagA é injetada nas células do epitélio gástrico através do T4SS e está fortemente implicada na carcinogénese gástrica. A VacA é responsável pela vacuolização celular e formação de poros na membrana, estando a sua expressão associada à expressão de CagA. A colonização pela $H$. pylori resulta em inflamação da mucosa gástrica com alteração do padrão de expressão de glicanos e aumento dos ligandos da adesina SabA (sLe e sLe $^{\mathrm{a}}$ ). A adesão mediada pela SabA resulta em ativação de neutrófilos com produção de metabolitos oxidados que vão promover o dano tecidular. A expressão da adesina SabA está associada à persistência da infeção. 
à H. pylori, independentemente do perfil de adesinas da bactéria, tendo sido demonstrado que estas microesferas são capazes de remover e prevenir a adesão da $H$. pylo$r i$ às células epiteliais gástricas. ${ }^{55} \mathrm{~A}$ maioria dos estudos com novos compostos terapêuticos que têm como alvo interferir com a adesão da $H$. pylori apresentam resultados promissores mas poucos mostram erradicação completa. Estes estudos avaliam a libertação destes compostos em $\mathrm{pH}$ ácido mas é também essencial avaliar componentes importantes para a adesão, como a atividade proteolítica e o peristaltismo. ${ }^{50,56}$

\section{CONCLUSÃO}

A erradicação da $H$. pylori é a melhor estratégia preventiva disponível contra o carcinoma gástrico, principalmente se feita antes do aparecimento de lesões pré-neoplásicas e está indicada em doentes de alto risco.

A utilidade de novos compostos terapêuticos que têm como alvo os mecanismos moleculares de adesão no tratamento da infeção por $H$. pylori é inquestionável, no entanto são necessários estudos futuros sobre a sua eficácia in vivo e toxicidade.

\section{CONFLITOS DE INTERESSE}

Os autores declaram que não possuem conflitos de interesses.

\section{FONTES DE FINANCIAMENTO}

Os autores declaram não ter recebido subsídios ou bolsas para a elaboração do artigo.

\section{REFERÊNCIAS}

1. Bastos J, Peleteiro B, Pinto H, Marinho A, Guimarães JT, Ramos E, et al. Prevalence, incidence and risk factors for Helicobacter pylori infection in a cohort of Portuguese adolescents (EpiTeen). Dig Liver Dis. 2013;45:290-5.

2. Porras C, Nodora J, Sexton R, Ferreccio C, Jimenez S, Dominguez RL, et al. Epidemiology of helicobacter pylori infection in six Latin American countries (SWOG Trial S0701). Cancer Causes Control. 2013;24:20915.

3. Bastos J, Peleteiro B, Barros R, Alves L, Severo M, de Fatima Pina $M$, et al. Sociodemographic determinants of prevalence and incidence of helicobacter pylori infection in Portuguese adults. Helicobacter. 2013;18:413-22.

4. Ohata H, Kitauchi S, Yoshimura N, Mugitani K, Iwane M, Nakamura $\mathrm{H}$, et al. Progression of chronic atrophic gastritis associated with helicobacter pylori infection increases risk of gastric cancer. Int $\mathrm{J}$ Cancer. 2004;109:138-43.

5. Ferlay J, Ervik M, Dikshit R, Eser S, Mathers C, Rebelo M, et al. GLOBOCAN 2012 v1.0, Cancer Incidence and Mortality Worldwide: IARC CancerBase No. 11, 2013. [consultado 2014 Jun 02]. Disponível em: https://www. http://globocan.iarc.

6. Peleteiro B, Lopes C, Figueiredo C, Lunet N. Salt intake and gastric cancer risk according to Helicobacter pylori infection, smoking, tumour site and histological type. Br J Cancer. 2011;104:198-207.

7. Noto JM, Gaddy JA, Lee JY, Piazuelo MB, Friedman DB, Colvin DC, et al. Iron deficiency accelerates helicobacter pylori-induced carcinogenesis in rodents and humans. J Clin Invest. 2013;123:479-92.

8. Salama NR, Hartung ML, Muller A. Life in the human stomach: persistence strategies of the bacterial pathogen helicobacter pylori. Nat Rev Microbiol. 2013;11:385-99.

9. Broz P, Monack DM. Molecular mechanisms of inflammasome activation during microbial infections. Immunol Rev. 2011;243:174-90.

10. Viala J, Chaput C, Boneca IG, Cardona A, Girardin SE, Moran AP, et al. Nod1 responds to peptidoglycan delivered by the helicobacter pylori cag pathogenicity island. Nat Immunol. 2004;5:1166-74.

11. Atherton JC, Blaser MJ. Coadaptation of helicobacter pylori and humans: ancient history, modern implications. J Clin Invest. 2009;119:2475-87.

12. Machado JC, Figueiredo C, Canedo $P$, Pharoah $P$, Carvalho R, Nabais S, et al. A proinflammatory genetic profile increases the risk for chronic atrophic gastritis and gastric carcinoma. Gastroenterology. 2003;125:364-71.

13. Duraes C, Munoz X, Bonet C, Garcia N, Vencesla A, Carneiro F, et al. Genetic variants in the IL1A gene region contribute to intestinal-type gastric carcinoma susceptibility in European populations. Int J Cancer. 2014;135:1343-55.

14. Kobayashi M, Lee H, Nakayama J, Fukuda M. Roles of gastric mucintype O-glycans in the pathogenesis of Helicobacter pylori infection. Glycobiology. 2009;19:453-61.

15. Dunne C, Dolan B, Clyne M. Factors that mediate colonization of the human stomach by Helicobacter pylori. World J Gastroenterol. 2014;20:5610-24

16. Magalhaes A, Marcos NT, Carvalho AS, David L, Figueiredo C, Bastos J,

et al. Helicobacter pylori cag pathogenicity island-positive strains induce syndecan-4 expression in gastric epithelial cells. FEMS Immunol Med Microbiol. 2009;56:223-32.

17. Kwok T, Zabler D, Urman S, Rohde M, Hartig R, Wessler S, et al. Helicobacter exploits integrin for type IV secretion and kinase activation. Nature. 2007;449:862-6.

18. Jimenez-Soto LF, Kutter S, Sewald X, Ertl C, Weiss E, Kapp U, et al. Helicobacter pylori type IV secretion apparatus exploits beta1 integrin in a novel RGD-independent manner. PLoS Pathog. 2009;5:e1000684.

19. Ferreira RM, Machado JC, Figueiredo C. Clinical relevance of helicobacter pylori vacA and cagA genotypes in gastric carcinoma. Best Pract Res Clin Gastroenterol. 2014;28:1003-15.

20. Fox JG, Wang TC. Inflammation, atrophy, and gastric cancer. J Clin Invest. 2007; 117:60-9.

21. Ferreira RM, Machado JC, Leite M, Carneiro F, Figueiredo C. The number of helicobacter pylori CagA EPIYA C tyrosine phosphorylation motifs influences the pattern of gastritis and the development of gastric carcinoma. Histopathology. 2012;60:992-8.

22. Olofsson A, Vallstrom A, Petzold K, Tegtmeyer N, Schleucher J, Carlsson $\mathrm{S}$, et al. Biochemical and functional characterization of Helicobacter pylori vesicles. Mol Microbiol. 2010;77:1539-55.

23. Lu H, Hsu PI, Graham DY, Yamaoka Y. Duodenal ulcer promoting gene of helicobacter pylori. Gastroenterology. 2005;128:833-48.

24. Schreiber S, Konradt M, Groll C, Scheid P, Hanauer G, Werling HO, et al. The spatial orientation of helicobacter pylori in the gastric mucus. Proc Natl Acad Sci USA. 2004;101:5024-9.

25. Azevedo M, Eriksson S, Mendes N, Serpa J, Figueiredo C, Resende $\mathrm{LP}$, et al. Infection by helicobacter pylori expressing the BabA adhesin is influenced by the secretor phenotype. J Pathol. 2008;215:308-16.

26. Ikehara Y, Nishihara S, Yasutomi H, Kitamura T, Matsuo K, Shimizu N, et al. Polymorphisms of two fucosyltransferase genes (Lewis and Secretor genes) involving type I Lewis antigens are associated with the presence of anti-Helicobacter pylori IgG antibody. Cancer Epidemiol Biomarkers Prev. 2001;10:971-7.

27. Lee HS, Choe G, Kim WH, Kim HH, Song J, Park KU. Expression of Lewis antigens and their precursors in gastric mucosa: relationship with Helicobacter pylori infection and gastric carcinogenesis. J Pathol. 2006;209:88-94.

28. Pinho SS, Reis CA. Glycosylation in cancer: mechanisms and clinical implications. Nat Rev Cancer. 2015;15:540-55.

29. Serpa J, Mendes N, Reis CA, Santos Silva LF, Almeida R, Le Pendu $J$, et al. Two new FUT2 (fucosyltransferase 2 gene) missense polymorphisms, 739G-->A and 839T-->C, are partly responsible for non-secretor status in a Caucasian population from Northern Portugal. Biochem J. 2004;383:469-74.

30. Silva LM, Carvalho AS, Guillon P, Seixas S, Azevedo M, Almeida R, et al. Infection-associated FUT2 (Fucosyltransferase 2) genetic variation and impact on functionality assessed by in vivo studies. Glycoconj J. 2010;27:61-8.

31. Lopez-Ferrer A, de Bolos C, Barranco C, Garrido M, Isern J, Carlstedt I, et al. Role of fucosyltransferases in the association between apomucin 
and Lewis antigen expression in normal and malignant gastric epithelium. Gut. 2000;47:349-56.

32. Silva E, Teixeira A, David L, Carneiro F, Reis CA, Sobrinho-Simoes J, et al. Mucins as key molecules for the classification of intestinal metaplasia of the stomach. Virchows Arch. 2002;440:311-7.

33. Kawakubo M, Ito Y, Okimura Y, Kobayashi M, Sakura K, Kasama S, et al. Natural antibiotic function of a human gastric mucin against Helicobacter pylori infection. Science. 2004;305:1003-6.

34. Appelmelk BJ, Negrini R, Moran AP, Kuipers EJ. Molecular mimicry between helicobacter pylori and the host. Trends Microbiol. 1997;5:70-3.

35. Ilver D, Arnqvist A, Ogren J, Frick IM, Kersulyte D, Incecik ET, et al. Helicobacter pylori adhesin binding fucosylated histo-blood group antigens revealed by retagging. Science. 1998;279:373-7.

36. Aspholm M, Olfat FO, Norden J, Sonden B, Lundberg C, Sjostrom R, et al. SabA is the $\mathrm{H}$. pylori hemagglutinin and is polymorphic in binding to sialylated glycans. PLoS Pathog. 2006;2:e110.

37. Mahdavi J, Sonden B, Hurtig M, Olfat FO, Forsberg L, Roche N, et al. Helicobacter pylori SabA adhesin in persistent infection and chronic inflammation. Science. 2002;297:573-8.

38. Yamaoka Y. Increasing evidence of the role of Helicobacter pylori SabA in the pathogenesis of gastroduodenal disease. J Infect Dev Ctries. 2008;2:174-81.

39. Magalhaes A, Reis CA. Helicobacter pylori adhesion to gastric epithelial cells is mediated by glycan receptors. Braz J Med Biol Res. 2010;43:6118.

40. Marcos NT, Magalhaes A, Ferreira B, Oliveira MJ, Carvalho AS, Mendes $\mathrm{N}$, et al. Helicobacter pylori induces beta3GnT5 in human gastric cell lines, modulating expression of the SabA ligand sialyl-Lewis $\mathrm{x}$. J Clin Invest. 2008;118:2325-36.

41. Magalhães A, Marcos-Pinto R, Nairn AV, Dela Rosa M, Ferreira RM, Junqueira-Neto $S$, et al. Helicobacter pylori chronic infection and mucosal inflammation switches the human gastric glycosylation pathways. Biochim Biophys Acta. 2015;1852:1928-39.

42. Merrell DS, Goodrich ML, Otto G, Tompkins LS, Falkow S. pH-regulated gene expression of the gastric pathogen helicobacter pylori. Infect Immun. 2003;71:3529-39.

43. Rossez Y, Gosset P, Boneca IG, Magalhaes A, Ecobichon C, Reis $\mathrm{CA}$, et al. The LacdiNAc-specific adhesin LabA mediates adhesion of helicobacter pylori to human gastric mucosa. J Infect Dis. 2014;210:128695

44. Posselt G, Backert S, Wessler S. The functional interplay of helicobacter pylori factors with gastric epithelial cells induces a multi-step process in pathogenesis. Cell Commun Signal. 2013;11:77.

45. Gerhard M, Lehn N, Neumayer N, Boren T, Rad R, Schepp W, et al. Clinical relevance of the helicobacter pylori gene for blood-group antigen-binding adhesin. Proc Natl Acad Sci USA. 1999;96:12778-83.

46. Malfertheiner P, Megraud F, O'Morain CA, Atherton J, Axon AT, Bazzoli $F$, et al. Management of helicobacter pylori infection - the Maastricht IV/ Florence Consensus Report. Gut. 2012;61:646-64.

47. Yaghoobi M, Farrokhyar $F$, Yuan $Y$, Hunt $\mathrm{RH}$. Is there an increased risk of GERD after helicobacter pylori eradication?: a meta-analysis. Am J Gastroenterol. 2010;105:1007-13.

48. Megraud F, Bessede E, Varon C. Helicobacter pylori infection and gastric carcinoma. Clin Microbiol Infect. 2015;21:984-90.

49. Gisbert JP, Calvet X. Review article: non-bismuth quadruple (concomitant) therapy for eradication of helicobater pylori. Aliment Pharmacol Ther. 2011:34:604-17.

50. Lopes D, Nunes C, Martins MC, Sarmento B, Reis S. Eradication of helicobacter pylori: Past, present and future. J Control Release. 2014;189:169-86.

51. Jagusztyn-Krynicka EK, Godlewska R. New approaches for helicobacter vaccine development--difficulties and progress. Pol J Microbiol. 2008;57:3-9.

52. Kleanthous H, Lee CK, Monath TP. Vaccine development against infection with helicobacter pylori. Br Med Bull. 1998;54:229-41.

53. Muller A, Solnick JV. Inflammation, immunity, and vaccine development for helicobacter pylori. Helicobacter. 2011;16:26-32.

54. Goncalves IC, Henriques PC, Seabra CL, Martins MC. The potential utility of chitosan micro/nanoparticles in the treatment of gastric infection. Expert Rev Anti Infect Ther. 2014;12:981-92.

55. Goncalves IC, Magalhaes A, Fernandes M, Rodrigues IV, Reis CA Martins MC. Bacterial-binding chitosan microspheres for gastric infection treatment and prevention. Acta Biomater. 2013;9:9370-8.

56. Nogueira F, Goncalves IC, Martins MC. Effect of gastric environment on helicobacter pylori adhesion to a mucoadhesive polymer. Acta Biomater. 2013;9:5208-15 